\title{
PUISI SISINDIRAN BAHASA SUNDA DI KABUPATEN BANDUNG (KAJIAN ISI DAN FUNGSI)
}

\section{SISINDIRAN IN KABUPATEN BANDUNG (A STUDY OF CONTENTS AND FUNCTIONS)}

\author{
Oleh Aam Masduki \\ Balai Pelestarian Nilai Budaya Bandung \\ Jl. Cinambo no. 136 Ujungberung-Bandung
}

\begin{abstract}
Abstrak
Menyindir Sindiran adalah salah satu bentuk Puisi Sunda lama yang terdiri atas sampiran dan isi. Namun demikian kepuisiannya terbatas pada rima dan irama, bukan pada diksi dan imajinasi seperti halnya puisi modern (sajak). Bahasanya mudah dipahami seperti bahasa seharihari. Sisindiran "pantun" merupakan Puisi rakyat yang sangat digemari masyarakat. Sisindiran dapat mengungkapkan perasaan, keadaan lingkungan, dan situasi masyarakat desa, petani, dan lain sebagainya. Biasanya dituturkan dalam suasana santai, berkelakar, dan suasana formal, misalnya dalam upacara adat perkawinan, melamar, dan sebagainya. Dalam perkembangannya, sangat luwes, mudah memasuki berbagai gendre sastra lainnya, seperti cerita pantun, wawacan, novel, cerpen, novelet bahkan muncul juga pada puisi modern. Penelitian ini menggunakan metode deskriptif analisis yaitu seluruh data yang diperoleh dari lapangan dikumpulkan, kemudian dianalisis dengan cara dikaji dan diklasifikasikan menurut struktur, isi, dan fungsi yang dikandungnya. Tujuan dari penelitian ini adalah (1) sisndiran dalam bentuk tertulis merupakan dokumentasi pengawetan karya sastra agar tidak mengalami kepunahan, (2) Menunjang kemudahan untuk menyusun sejarah sastra, serta pengembangan teori sastra, khsusnya sastra lisan Sunda, (3) Hasil pendokumentasian ini akan bermanfaat untuk perbendaharaan bahasa, sastra, dan budaya daerah. Hasil dari penelitian diharapkan menjadi bahan bacaan yang dapat menuntun generasi berikut ke jalan kebaikan melalui ungkapan yang disampaikan secara langsung atau tidak langsung.
\end{abstract}

Kata kunci : puisi, sisindiran, bahasa Sunda.

\begin{abstract}
Sisindiran is a form of old Sundanese poetry consisting of sampiran (metaphors) and contents. It has rhyme and rhythm at the end of each word and it uses simple, easily understood daily language. Sisindiran is used either to express feelings or describe environment and presented in various situations both formal and informal. It can easily easily blend with other literary genres. No wonder if sisindiran is very popular folk poetry. The purpose of this study is 1) documenting folk literatures in written form, 2) supporting research in compiling literature history as well as developing literary theory, especially of Sundanese oral literatures. This
\end{abstract}


documentation would enrich repertoire of regional literatures in Indonesia. In doing the research the author conducted descriptive analytical method.

Keywords: poetry, sisindiran, Sundanese language

\section{A. PENDAHULUAN}

Sisindiran adalah salah satu bentuk puisi Sunda lama yang terdiri atas sampiran dan isi. Namun demikian kepuisiannya terbatas pada rima dan irama, bukan pada diksi dan imajinasi seperti halnya puisi modern (sajak). Bahasanya mudah dipahami seperti bahasa sehari-hari. Dalam Sastra Indonesia biasa disebut pantun. Sisindiran "pantun" merupakan puisi rakyat yang sangat digemari masyarakat di kalangan anak-anak, remaja maupun orang tua. Sisindiran dapat mengungkapkan atau mencerminkan perasaan, keadaan lingkungan, dan situasi masyarakat desa, petani, pendidikan, dan sebagainya. Biasanya dituturkan dalam situasi santai, berkelakar, berbincang-bincang, dan suasana formal, misalnya dalam upacara adat perkawinan, melamar, dan sebagainya. Itulah kemungkinan yang menyebabkan genre sisindiran ini sangat memasyarakat.

Dalam perkembangannya sisindiran sangat luwes, mudah memasuki berbagai gendre sastra lainnya, seperti cerita pantun, wawacan, novel, cerpen, novelet, bahkan kadang-kadang muncul juga pada puisi modern. Kini sisindiran tampaknya tidak mau ketinggalan, ia dapat ditayangkan di televisi dan materinya sangat menarik perhatian serta diminati oleh masyarakat. Oleh karena itu kiranya perlu dilakukan penelitian terhadap fungsi sisindiran yang tersebar di masyarakat, dan perlu dikumpulkan untuk didokumentasikan.

Permasalahan yang dikaji dalam penelitian ini berkaitan dengan struktur fungsi dan isi sisindiran. Dari segi strukturnya, sisindiran dibagi menjadi tiga golongan yaitu : Paparikan, Rarakitan, dan Wawangsalan. Sampiran dan isi dalam paparikan mempunyai persamaan bunyi yang berdekatan, misalnya :

Ari reundeu-reundeu hideung

Reundeu kayas kolentangan

Beuki heubeul beuki nineung

Lawas-lawas kaedanan

Maksud dari sisindiran di atas yaitu: makin lama makin rindu, lama-lama bisa tergila-gila.

Adapun rarakitan bukan saja persamaan bunyi namun ada kata-kata yang disebut dalam sampiran diulang lagi dalam isi misalnya :

Sapanjang jalan Soreang 
Moal weleh diaspalan

Sapanjang tacan kasorang

Moal weleh diakalan

Maksud dari rarakitan tersebut adalah: selama belum tercapai tak akan bosan diakali. Kata sapanjang dalam sampiran diulang lagi pada isinya, demikian pula kata moal weleh diulang lagi pada larik isi, lain halnya dengan wawangsalan, merupakan bentuk yang agak berbeda yaitu pada baris pertama mengandung teka-teki yang harus diterka, pada baris kedua mengandung isi terkaan yang dinyatakan dengan sebuah kata yang mirip, misalnya :

Beulit cinggir simpay tangan

Ulah lali ka sim abdi (Ali) "Cingcin"

Sisindiran merupakan salah satu unsur kebudayaan daerah yang cukup bernilai dan dapat memperkaya khasanah budaya Indonesia umumnya dan budaya daerah khususnya. Adapun tujuan yang ingin dicapai adalah sebagai berikut :

1. Adanya sisindiran dalam bentuk tertulis merupakan dokumentasi pengawetan karya sastra agar tidak mengalami kepunahan.

2. Menunjang kemudahan untuk menyusun sejarah sastra, serta pengembangan teori sastra, khsusnya sastra lisan Sunda.

3. Hasil pendokumentasian ini akan sangat bermanfaat untuk perbendaharaan bahasa, sastra, dan budaya daerah.

4. Dapat dijadikan acuan dan bahan penelitian yang lebih lanjut.

Dalam rangka melaksanakan tujuan penelitian, maka ruang lingkup ini akan dibatasi hanya mengenai hal-hal yang menyangkut pada : Nilai-nilai yang terkandung dalam puisi sisindiran.

Penelitian ini menggunakan metode kualitatif yaitu seluruh data yang diperoleh dari lapangan dikumpulkan, kemudian dianalisis dengan cara dikaji dan diklasifikasikan menurut struktur, isi, dan fungsi yang dikandungnya. Teknik pengumpulan data dilakukan dengan cara pencatatan yaitu setiap data yang didapat ditulis dan dikumpulkan kemudian diklasifikasikan menurut golongan sisindiran.

\section{B. HASIL DAN BAHASAN}

\section{Pengertian Sisindiran}


Di dalam naskah Sunda Kuno Sanghyang Siksa Kandang Karesian (Atja dan Saleh Danasasmita, 1981) yang di tulis pada tahun 1518 Masehi, Sisindiran merupakan bidang kawih, yaitu salah satu jenis suara (vokal) dalam kesenian Sunda.

Pengertian sisindiran sekarang cenderung lebih banyak digunakan dalam pembicaraan bidang sastra. Sisindiran adalah sejenis puisi tradisional yang terikat oleh beberapa persyaratan bentuk. Dalam masa sekarang pun bisa dikatakan bahwa sisindiran erat hubungannya dengan seni kawih. Serta dapat dibawakan dalam bermacam-macam jenis kesenian misalnya reog, calung, wayang golek. Di samping itu sisindiran sering digunakan untuk bergurau.

Dilihat dari pembentukannya, kata sisindiran berasal dari bentuk dasar sindir. Dengan demikian sisindiran merupakan bentuk kata jadian yang diperoleh dengan cara dwipurwa (pengulangan awal) disertai akhiran-an. Berdasarkan arti kata asalnya dapat diketahui pula bahwa yang menjadi patokan sisindiran bukan hanya bentuknya, melainkan isinya, yaitu berupa sisindiran atau bersifat menyindir.

\section{Klasifikasi Sisindiran}

R. Satjadibrata (1945) mengelompokkan sisndiran menjadi dua macam bentuk yaitu : (1) Paparikan dan (2) Wawangsalan. Adapun contoh dari paparikan tersebut adalah sebagai berikut:

Samping hideung dina bilik "Kain hitam pada dinding" kumaha dituhurkeunanan " bagaimana dikeringkannya" kuring nineung ka nu balik " aku rindu pada dia yang pulang" kumaha dituturkeunana "bagaimana harus dibarenginya"

Contoh Wawangsalan :

Teu beunang dihurang sawah " Tak bisa diudang sawah" teu beunang dipikameumeut " tak bisa disayangi"

Perbedaan antara paparikan dan wawangsalan terlihat pada kedua contoh di atas. Satu bait pada paparikan terdiri atas empat larik yang terbagai atas dua bagian, yaitu bagian sampiran dan bagian isi, yang berturut-turut terdiri atas larik ke-1 dan larik ke-2, dan larik ke-3 dan larik ke-4, setiap larik terdiri atas empat suku kata. Persajakan (purwakanti) terdapat pada ujung larik secara bersilang. Larik ke-1 bersajak dengan larik ke-3, larik ke-2 bersajak dengan larik ke-4.

Satu bait wawangsalan hanya terdiri atas dua larik, tetapi tetap terbagi atas dua bagian, yaitu bagian sampiran dan bagian isi. Persajakannya terdapat pada ujung larik, namun tidak bisa langsung terlihat maupun terdengar. Persajakan baru terjadi bila wangsal "teka-teki" pada larik ke-1 sudah ditemukan. Usaha menemukan wangsal itu harus memerhatikan larik isi atau larik ke- 
2. Contoh : Teu beunang dihurang sawah. Wangsal yang harus dicari ialah hurang sawah "udang sawah", udang yang hidup di sawah yaitu simeut "belalang".

Ditemukannya wangsal itu karena petunjuk dari larik ke-2 yang berbunyi teu beunang dipikameumeut. Kata dipikameumeut yang bersajak dengan kata simeut merupakan kata kunci untuk ditemukannya wawangsalan. Rincian perbandingan antara paparikan dan wawangsalan akhirnya menyimpulkan bahwa unsur yang menjadi ciri utama puisi sisindiran ialah adanya bagian sampiran dan isi.

Menurut R.E Bratakusumah dan Mas Adinata (1979) memberikan keterangan yang hampir sama. Pengelompokan yang dibuatnya mengenai puisi sisindiran pada dasarnya sama dengan pengelompokan yang dibuat oleh R. Satjadibrata, yaitu bahwa sisindiran terbagi atas dua golongan besar yaitu : (1) Wawangsalan dan (2) Paparikan. Dengan demikian memperbandingkan kedua pendapat mengenai pengelompokan sisindiran itu, diketahui bahwa klasifikasi R. Satjadibrata lebih terperinci.

\section{Struktur Sisindiran}

Puisi sisindiran terikat oleh beberapa aturan bentuk, yaitu banyaknya larik dalam setiap bait, banyaknya suku kata dalam setiap larik, serta oleh persajakan (purwakanti).

Paparikan dan rarakitan menunjukkan bentuk yang hampir persis sama. Setiap bait terdiri atas empat larik, dua larik pertama sebagai sampiran dan dua larik terakhir sebagai isi. Setiap larik terdiri atas delapan suku kata. Keempat larik tersebut bersajak"murwakanti" sekurang-kurangnya pada suku kata terakhir, serta bersilang, larik ke-1 dengan larik ke-3, larik ke-2 dengan larik ke-4. Misalnya pada paparikan berikut :

Boga lima botol limun "Mempunyai lima botol limun" cangkirna dina rampadan "cangkirnya dalam rampadan jelema getol ngalamun "orang yang banyak mengkhayal" ahirna kurang saeundan "akhirnya pikirannya terganggu"

Dalam paparikan tersebut terlihat bahwa persajakan tidak hanya pada ujung larik, melainkan juga terdapat di awal dan di tengah larik. Satu bait wawangsalan terdiri atas dua larik, larik kesatu sampiran, larik kedua isi. Tiap larik terdiri atas delapan suku kata. Seperti wawangwasalan berikut :

Cisusu kentel dimasak "Air susu kental dimasak" ulah tega-tega teuing "jangan sampai hati" 
Wangsal yang tersembunyi pada larik sampiran adalah mentega. Bunyi kata mentega itu berdekatan dengan kata tega-tega. Tega-tega merupakan kata kunci serta menjadi isi wawangsalan.

\section{a. Sisindiran}

Perbedaan antara wawangsalan dengan kedua jenis sisindiran; paparikan dan rarakitan, tidak hanya berbeda bentuknya, melainkan berbeda pula dalam hal isinya. Wawangsalan lebih banyak digunakan untuk mengungkapkan curahan perasaan kasih sayang (kerinduan), gelisah, kesetiaan, rasa perasaan, harapan, bersedih, dan sebagainya. Misalnya wawangsalan berikut ini :

Belut sisit saba darat "Belut bersisik yang hidup di darat " : oray "Ular" kapiraray siang wengi "terbayang-bayang siang dan malam"

Kecil kemungkinannya untuk digunakan sebagai ekspresi kerinduan dua orang sahabat apalagi berbeda jenis. Senandung kerinduan seperti itu lebih sesuai untuk sepasang remaja yang sedang memadu kasih. Isi paparikan dan rarakitan lebih beraneka ragam, pada garis besarnya dapat digolongkan kedalam tiga kelompok yaitu : (1) silih asih (berkasih-kasihan), (2) piwuruk (nasihat), dan (3) sesebred (lelucon).

\section{b. Nilai-nilai dalam puisi sisindiran}

Menurut kamus Besar Bahasa Indonesia, nilai adalah konsep mengenai masalah dasar yang sangat penting. Nilai adalah sesuatu yang abstrak yang tidak dapat dilihat secara nyata.

Nilai-nilai yang terkandung dalam puisi sisindiran bahasa Sunda sangat banyak, namun pada kesempatan ini hanya sebagian yang dapat diuraikan. Hal ini karena adanya pertimbangan dan keterbatasan jumlah halaman yang membatasinya. Adapun nilai-nilai tersebut di antaranya adalah sebagai berikut :

\section{1) Nilai Pendidikan}

Samping kageutahan dukuh dikelab di kacaikeun

nu matak maneh sing kukuh

papatah geura imankeun

Pulas batis encit muntah

meulina ti anu kumed

reungeukeun kami papatah

ulah resep ceceremed 
Memeh ngagolerkeun kasur samak heula ambeh rineh memeh nyaritakeun batur tilik heula awak maneh

Pikasureun dijarumat jarumna harga sasen saluhureun kudu hormat sasama kudu ajenan

Mawa peti dina sundung dibawa ka nusa Jawa pangarti teu beurat nanggung kabisa teu beurat mawa

Mawa peti dina sundung ditumpangan ku karanjang pangarti teu beurat nanggung tapi manfaatna manjang

Jiga naon lauk enun matak jadi kaheranan mun maneh cucud jeung junun insya allah tinekanan

Lauk emas ngakan ganggeng disamberan ku japati boga emas moal langgeng teu cara boga pangarti

Ngala lauk meunang selar bungkusna daun angsana sakur mahluk nu gumelar dirahmat ku nu Kawasa

Hurang leuwi cicing deui dina sumur kasaatan beurang deui peuting deui tetela umur ngorotan

Angeun hurang sapariuk bawangna ngan dua sihung ulah mungpang kapiwuruk bisi ahirna kaduhung

Hayang iwung los ka Bandung rek ngasah los ka Sumedang hayang bingung geura nyandung rek susah sing boga hutang

Mun haur cukang tiguling 
tangtu hese nungtun munding

mun campur jeung tukang maling

tangtu maneh milu maling

Mawa kisa jeung bakatul hanggasa ngarora keneh moal bisa ngurus batur

mun teu bisa ngurus maneh

Kiripik dihakan jangkrik dina samak buatan jogya lamun teu apik teu rikrik alamat taya kaboga

Limun dicampur ciatah bangkarak bungkus papais geura mun nurut papatah awak maneh tangtu luis

\section{2) Nilai Agama}

Nu ngaliwet dina dulang disuluhan ku palapah saha nu resep tutulung meunang ganjaran ti Allah

Meuli wajit jeung jawadah dipake hajat kiparat masing rajin nya ibadah ngalap ganjaran aherat

Sorabi make cipati didahar seep sawadah nya rabi titipan gusti dikadar kuat ibadah

Ninyuh ubar ku cipati diwadahan piring gelas anu sobar tea pasti ku Allah dipikawelas

Sing getol nginum jajamu ambeh jadi kuat urat sing getol neangan elmu guna dunya jeung aherat

Bubur waluh dina panci diawuran ku candana Gusti anu Maha Suci Henteu samar ka umatna 
Jajambaran bubur lemu kelewih picung diruang untung jalma loba elmu leuwih ti beunghar ku uang

Camcauh kahalodoan

jadina handapeun nangka ari mungguh kabodoan nungtunna kana doraka

Meuli limun meuli soldah meuli baligo jeung huni mun ayeuna teu ibadah ngadagoaan naon deui

Batok golerkeun di dapur eusikeun parab merina nu sok ngagorengkeun batur nembongkeun cacad dirina

Mawa ragi ka Cilutung tikukur ngudag saeran boh rugi atawa untung kudu sukur ka Pangeran

Kored parang lain timah ulah dikanabatukeun naon nu kurang teu ngeunah ulah sok dikabaturkeun

Sarangka dina talupuh pesona mah dina pager ulah sok nyangka teu puguh mun maneh teu nyaho bener

Kacapiring kembang jambe ekek paeh dinu lenang tandaning jalma nu hade daek eleh sungkan meunang

Kembang pala kembang kadu ditiiran ku panitih kapala nu resep ngadu nyarek maen moal matih

Kembang beukah dina nyiru 
baruyeng ku haranghangsu

mangpaatna ku berkah guru

mayeng upama cinyusu

Kembang cangkudu bareukah

diteundeun di tengah imah

hirup kudu amal sidkoh

masing tulung kanu pupus

Daun solasih ngareluk

diseumat ku awi beulah

nu asih ka pada mahluk

dirahmat ku Gusti Allah

Morontod pelak solasih

daunna dipake ubar

ulah sok kaburu asih

teu aya batan nu sabar

Tangkal hanggasa di sawah

buahna kabeh galede

sagala keresa Allah

eta kabeh oge hade

\section{3) Nilai Berkasih-kasihan}

Pileuleuyan daun pulus

kararas cau manggla

pileuleuyan tungtung imut

lamun welas kuring bawa

Kasur jangkung bantal panjang

nya bogo di kacaikeun

anu jangkung kuring melang

nya bogoh urang jadikeun

Sukur-sukur disundungan

kuring mah nyair ka leuwi sukur-sukur dipundungan

kuring mah rek nyiar deui

Kuring mah alim ka Bandung

hayang ka Sumedang bae

kuring mah alim dicandung

hayang ku sorangan bae

Baju tablo dibulao

kembangna katuncar mawur 
ari bogoh ti bareto

terang-terang tos ku batur

Ngaput baju kurang benang gantian ku kanteh bae mun panuju geura teang kuring mah rek daek bae

Ngimpi ngajul kembang tanjung ngimpi ngala naga sari ngimpi tepung jeung si jangkung tara-tara ti sasari

Kembang puring dipipitan kembang saga na panglari ayeuna kuring pamitan sugan jaga tepang deui

Melak solasih di pasir ngarambat kana kadaka kajeun teu kawin di lahir supaya dikawin jaga

Ngala suluh ka Cililin acan kakejo parena ulah rusuh ngajak kawin acan ketenjo hadena

Ngala pangpung meunang ruyung ngala regang ka lebak gering nangtung ngalanglayung lantaran kaleleban

Ngala suluh ka Cicurug ngala regang ka Ciheulang najan jauh kuring jugjug najan anggang kuring teang

Cileuncang cai cileuncang cileuncang dipake ngarih isukan kuring rek leumpang pageto moal papanggih

Cai ngumplang dina dulang keuyeup nyarangkaan maneh hayu akang urang mulang di dieu nyangsara maneh

Ngala bogo ka sagara ngala penyu ka basisir 
nya bogoh ulah katara

neundeun semu dina pikir

Beunteur beureum bodas beuteung

paray naek katampian

anu heubeul geura piceun

kuring daek ngagantian

Lauk cucut lauk emas

disair ku lambit jaring

matak lucu matak waas

matak nyuat ati kuring

Mubuy bulan nyangray bentang

panon poe disasate

unggal bulan kuring teang

unggal poe bisi cape

Panonpoe dengdek ngaler

kahalangan daun cau

hate teu daek paler

inget bae ka nu lucu

Panas poe panyacaran

lain panas kahuruan

panas soteh panasaran

lain panas timburuan

Santiong astana cina

opor meri dina piring

ngabohong kabina-bina

nganyenyeri diri kuring

Sakoteng dagangan cina diwadahan pisin cangkir nu hideung santen lucu kacida matak ngait kana pikir

Baju tablo dibulao cing atuh pangistrikakeun ari bogoh tibareto cing atuh pangnyaritakeun

Batur mah baju kimono puring mah dikaparakeun batur mah dipikasono kuring mah disapirakeun

Leumeung teundeut cocongoan jalanna ka rajagaluh 
meungpeung deukeut sosonoan

jaga mah urang pajauh

Manuk ciung dikempisan

rambutan aratah keneh

dicium kunu kumisan

sabulan karasa keneh

\section{4) Nilai Lelucon Menyindir (Sesebred)}

Isuk katung sore katung kantungna siga popongkol isuk nangtung sore nangtung sarungna hiji ge dobol

Baju katung kancing katung hoream ngajaranana nyiar untung nyiar hutang hoream mayaranana

Turub cupu buli-buli dipake wadah hanggasa daek sukur teu paduli kami ge da moal maksa

Pipiti dikurah-karih tetenong dibobokoan lalaki jaman kiwari hade omong pangoloan

Nu ngaliwat bau bawang sampingna bau tarasi kanu ngaliwat kuring hayang mun seug teu boga salaki

Tarik angin ngadalingding ninggang kana pare beukah ditarik kawin ngaligincing teu bogaeun keur ipekah

Hapeuk-hapeuk gula tiwu leeh soteh kahujanan aceuk-aceuk kuring milu leweh soteh kaedanan

Montong sok hayang surundeng kalapa di Bandung keneh montong sok hayang ka ronggeng balanjan ti indung keneh 
Piring katuruban sendok ngawadahan rujak huni kuring ge baheula denok ayeuna mah nini-nini

Boboko ragrag ti para ninggang kana pileuiteun tong bogoh kanu ngumbara ari balik sok leungiteun

Nganyam teu bisa ngalepe bisa ngabayongbong bae daek ngajang embung mere bisa ngadu omong bae

Melak ganas dina gombong sahiji di kacaikeun ari panas geura ngomong pasini geura jadikeun

Melak kacang dilanjaran melak jagong diterongan eukeur hayang didatangan eukeur bogoh ditembongan

Melak kacang dina batu ditanggeuhan kele kosong anu nganjang geus ngabaku diteang dompetna kosong

Cau kepok cau raja cau lampeneng karoneng alus repok gede bagja ngiringkeun nu pendek koneng

Cau kulutuk ditanggung cau manggala dirujak kulutus hayang nyandung dicarek ku indung budak

Rarasaan melak cau teu nyaho mun melak jahe rarasaan asa lucu teu nyaho mun matak rehe

Majar teh cau lampeneng cau kepok dina nyiru majar teh lampanyat koneng geuning nya dekok nya gembru 
Cau raja seuseuhangna neangan kujang kadekeun aya randa leuleumpangan neangan bujang daekeun

Ecet-ecet dina kadu dikeprakan ku barangbang kasep ge da tukang ngadu ari balik ditaranjang

Peupeuyeuman-peupeuyeuman diragian ge teu amis peupeureuman-peupeureuman diponian ge teu geulis

Peuyeum nangka-peuyeun nangka peuyeum sampeu dipotongan meureun suka-meureun suka da deukeut jeung popotongan

Panyana enya muncang singhoreng tangkal bintinu panyana enya bujang horeng geus incuan tilu

Kaduhung kadongdong cina nyiuk cai ku elekan kaduhung kabina-bina nyebut nyai didelekan

Kasedep ngarujak pakel diwadahan piring batu seselendep nongton ogel panyana teh neangan incu

Kacapiring dina kajang diteundeun dina kaliki kuring baheula mah bujang ayeuna aki-aki

Kacapiring-kacapiring si lutung luncat ka tungtung bujang ginding-bujang ginding ari udud mulung kuntung

Hiliwir seungit malati seungit minyak dina kompor hiliwir seungit lalaki seungit menak jol ti kantor 
Aya kawung sisi lembur ditinggur ku dadap ngora bujang guyur salelembur marebutkeun randa ngora

Daun endag angin malik dikebut ku saputangan ngudag-ngudag lain milik tungtungna era sorangan

Abong-abong daun lompong daun cabe dikebutkeun abong-abong kanu ompong datang cape dibaeudan

kanyere di pasir pari tangkal kujang diamalan awewe jaman kiwari unggal bujang dilayanan

Ku naon kanyere semplak mana semplak ku tiwuan ku naon awewe nyentak mana nyentak timburuan

Manuk ciung dikempisan rambutan aratah keneh dicium kunu kumisan sabulan karasa keneh

Daringding kacang gumading isukan di ka caikeun ginding ge da meunang maling isukan di kabuikeun

Melak saledri teu jadi kaburu ku bongborosan rek jadi santri teu jadi kaburu ku bobogohan

Hanjakal ku handarusa buntiris daunna kandel hanjakal ku hade rupa geulis teu bisa nyambel

Hayam jalak hayam kondang pais endog atah keneh teu diajak teu diondang ka dieu mantog ku maneh 


\begin{abstract}
Kini-kini dina galeng
rek katincak ku tikukur

nini-ni hulang huleng

rek diwedak euweuh pupur

Hujan deui-hujan deui

hujan ngarincik ngagebret

bujang deui bujang deui

bujang nya licik nya kopet
\end{abstract}

Asa kadu-asa kadu

susu belut reujeung jambal

asa payu-asa payu

susu rayud buuk gimbal

Sejarah mencatat bahwa masyarakat dan kebudayaan suku-suku bangsa di Nusantara telah banyak melahirkan para pujangga, karya-karya tulis mereka banyak yang pengaruhnya cukup besar dan bernilai tinggi. Hal demikian, tentu termasuk pula di dalam masyarakat dan kebudayaan Sunda. Para pujangga atau sastrawan Sunda telah muncul sejak berabad-abad yang lampau seiring dengan perjalanan sejarah dan perkembangan jaman. Sesuai dengan pergantian zaman dan generasi, maka para sastrawan Sunda pun berganti-ganti generasi. Masing-masing berasal dari dan dipengaruhi oleh tiap-tiap zaman serta sosial budaya setempat dan waktu mereka dibesarkan.

Pada umumnya karya-karya sastra para pujangga lama hingga kini masih tetap diagungkan, karena selain mengandung kekayaan rohani, perbendaharaan pikiran, dan cita-cita nenek moyang yang luhur. Salah satu karya-karya para pujangga tersebut yang kini masih digemari dan dirasakan keberadaannya yaitu puisi sisindiran bahasa Sunda.

Sastra menampilkan gambaran kehidupan yang mencakup hubungan antara masyarakat, antara masyarakat dengan seseorang, dan antarmanusia; peristiwa-peristiwa yang terjadi dalam batin seseorang, yang sering menjadi bahan sastra adalah pantulan hubungan seseorang dengan orang lain atau dengan masyarakat (Sapardi, 1978:1). Karya sastra klasik dengan demikian dapat dijadikan bahan untuk merekontruksi tatanan masyarakat, pola-pola hubungan sosial, aspirasiaspirasi, sistem nilai budaya yang didukung oleh masyarakat dimana karya sastra itu lahir, serta situasi yang berlangsung pada waktu itu. Dengan kata lain, karya-karya sastra lama dapat dijadikan sebagai sumber informasi untuk mengetahui dan memahami zaman yang telah lampau.

Mengkaji suatu karya sastra dengan tujuan untuk memahami keadaan masyarakat tidak cukup hanya dengan menelaah karya sastra itu dari segi filologi atau kritik teks saja, tetapi perlu juga pendekatan litere antara lain melalui struktur yang akan jelas menampilkan pokok pikiran di 
seluruh cerita dan bagian-bagiannya sampai yang paling kecil. Dengan demikian akan muncul fungsi cerita itu, karena tiap teks atau cerita dilahirkan guna memenuhi suatu fungsi (Sulastin, $1979: 62)$.

Atas dasar hal tersebut di atas, maka dapat dikatakan bahwa fungsi puisi sisindiran dalam suatu masyarakat adalah sebagai berikut :

a) Sebagai pengendali tingkah laku anggota-anggota masyarakat agar mereka patuh dan taat pada kaidah-kaidah, norma-norma, atau aturan-aturan yang telah ada dalam masyarakat. Atau dapat pula dikatakan sebagai fungsi untuk mengarahkan tingkah laku anggota-anggota masyarakat agar tidak menyimpang dari ketentuan-ketentuan yang ada dalam kehidupan masyarakat.

b) Sebagai suatu sistem dan cara untuk mempertahankan kelangsungan hidup dan eksistensi masyarakat secara keseluruhan dan untuk meneruskan adat-istiadat, kebiasaan-kebiasaan, kepercayaan-kepercayaan, dan larangan-larangan atau pantangan-pantangan yang sudah ada dalam masyarakat dari generasi ke geneasi berikutnya.

c) Berfungsi sebagai pengatur, pengendali, dan pengawasan, agar dapat diciptakan kehidupan masyarakat yang serasi, selaras dan seimbang untuk mewujudkan ketertiban, ketentraman, dan kesejahteraan seperti yang diinginkan bersama oleh anggota suatu masyarakat.

d) Sebagai alat untuk memperkokoh struktur dan integritas masyarakat secara keseluruhan dalam menciptakan persatuan dan kesatuan di antara warga suatu masyarakat.

e) Berfungsi untuk menumbuhkan perasaan cinta akan lingkungan dan keinginan untuk melestarikan lingkungan hidup di mana anggota masyarakat bertempat tinggal.

Jika dilihat dari fungsinya, puisi sisindiran memiliki fungsi sebagai pengaturan tingkah laku anggota-anggota masyarakat atau sebagai pedoman yang seharusnya digunakan oleh warga masyarakat dalam melaksanakan kegiatan hidupnya untuk menciptakan suasana kehidupan masyarakat yang tertib, aman dan sejahtera.

Sikap hidup beragama orang Sunda tercermin dalam intensitas hubungan manusia dengan Tuhan Yang Mahaesa. Orang Sunda percaya bahwa segala sesuatu yang terjadi pada manusia sudah ditentukan oleh Tuhan Yang Mahaesa, seperti terungkap dalam bait puisi sisindiran berikut ini :

Meuli limun meuli soldah

meuli baligo jeung hui

mun teu ayeuna teu ibadah

ngadagoan naon deui

Colok-colok daun ilat
Beli limun beli soldah

beli baligo dan hui

kalau sekarang tidak beribadah

menunggu apa lagi

Colok-colok daun ilat 
dieunteupan manuk kahkeh

geus kolot sing getol solat

kudu inget bakal paeh

Meuli wajit jeung jawadah

dipake hajat kiparat

masing rajin nya ibadah

ngalap ganjaran aherat

Mawa ragi ka Cilutung

tikukur ngudag saeran

boh rugi atawa untung

kudu sukur ka Pangeran

Simeut disamber saeran

dibawa kana pisitan

nu teu nyembah ka Pangeran

pasti jadi balad setan dihinggapi burung kahkeh

sudah tua harus rajin sholat

harus ingat akan mati

Beli wajit dan jawadah

dipakai hajat kiparat

harus rajin beribadah

untuk bekal di akhirat

Membawa ragi ke Cilutung

tekukur mengejar saeran

mendapat untung atau rugi

harus bersyukur kepada Tuhan

Belalang disambar saeran dibawa kepada pisitan

yang tidak menyembah Tuhan

pasti jadi balad setan

Agama memberikan tuntunan kepada manusia, baik mengenai kehidupan di dunia maupun kehidupan di akhirat. Oleh karena itu ajaran agama memilki dua aspek, yaitu ajaran yang mengharuskan manusia hidup baik di dunia ini dan untuk mencapai kehidupan yang baik di akhirat kelak. Dengan demikian agama mengajarkan tentang hubungan antara sesama dan tentang hubungan manusia dengan Tuhan Yang Mahaesa. Adapun ajaran yang utama ialah agar manusia melaksanakan perintah-perintah-Nya dan menjauhi larangan-larangan-Nya.

Pandangan hidup orang Sunda tentang hubungan manusia dengan masyarakat menampilkan nilai-nilai dalam wujud kaidah-kaidah sosial; di dalamnya terletak keyakinan orang Sunda atas apa yang baik dan buruk, yang benar dan yang salah. Dalam kehidupan seharihari kaidah sosial tampil dalam bentuk suruhan atau keharusan, larangan atau celaan, anjuran dan pujian. Demikian pula di dalam perilaku seseorang, kata "kudu" (harus) menunjukkan suruhan atau keharusan, kata "ulah" (jangan) menunjukkan larangan. Tiap-tiap kata itu di dalam ujaran dipakai baik secara berdiri sendiri maupun secara berpasangan dengan kata-kata lain yang menunjukkan pada akibat yang akan menimpa itu tersimpul dalam kata-kata yang mengandung ancaman, hukuman, semua ini ditunjukkan oleh kata-kata "ngarah" (supaya), "matak" (nanti akan) dan "bisi" (kalau-kalau), seperti tersirat dalam kata-kata yang terdapat dalam puisi sisindiran berikut ini :

Urang desa gunung bohong

resepna kana tarumpah

poma pisan ulah bohong

sagala ning laku lampah
Orang desa gunung bohong

menyukai pada terumpah

jangan suka berbohong

dalam setiap perbuatan 
Kamana nya pelesiran

ka ditu ka parapatran

lampah nu goreng singkiran

lampah nu hade turutan

Manuk ekek leuwih aneh

nerekel naek ka luhur

mending oge nyarek maneh

batan dicarekan batur

Tonggeret di jalan belot

eunteup dina tangkal nangka

saha nu goreng ka kolot

eunggeus tinangtu doraka
Kemana berjalan-jalan ke sana ke perempatan perbuatan yang jelek jauhi perbuatan yang baik harus ditiru

Burung ekek lebih aneh memanjat ke atas lebih baik menahan diri dari pada dimarahi orang lain

Tonggeret di jalan berbelot hinggap pada pohon nangka siapa yang memusuhi orang tua pasti durhaka

Ketentraman hidup tampaknya merupakan motif utama dalam hidup bermasyarakat menurut pandangan hidup orang Sunda. Orang Sunda tidak suka konflik, karena konflik akan menimbulkan keonaran dalam bermasyarakat, sehingga ketentraman bisa terganggu. Supaya hidup tentram, maka dalam pergaulan orang harus bertindak hati-hati, waspada. Sejak bayi, sekalipun secara simbolis kehati-hatian itu sudah ditanamkan. Dari adat-istiadat kita dapatkan sejumlah ujaran seperti ini :jangan sembarang berkata, jangan sembarang mencium bebauan, jangan sembarang melihat, jangan sembarang masuk, dan lain sebagainya. Ada hubungan yang erat antara keselamatan seorang dengan ketentraman masyarakat. Dalam masyarakat yang tentram, keselamatan seseorang tentu akan lebih terjamin daripada di dalam masyarakat yang penuh perpecahan dan kekacauan.

\section{PENUTUP}

Berdasarkan uraian-uraian dalam bab-bab terdahulu yang berisi latar belakang masalah, permasalahan, tujuan penelitian, pengertian sisindiran dan lain sebagainya dapat dikemukakan secara umum bahwa sisindiran sekarang lebih banyak digunakan dalam pembicaraan bidang sastra. Bila dilihat dari pembentukannya, sisindiran berasal dari bentuk dasar sindir. Dengan demikian sisindiran merupakan bentuk kata jadian yang diperoleh dengan cara dwipurwa (pengulangan awal) disertai akhiran-an.

Berdasarkan arti kata asalnya dapat diketahui pula bahwa yang menjadi patokan sisindiran bukan hanya bentuknya, melainkan juga isinya, yaitu berupa sindiran atau bersifat menyindir. Dari pembentukan kata tersebut bahwa yang dimaksud dengan kata sindir yaitu ungkapan atau kata-kata dengan cara perkataan secara tidak langsung. Artinya perkataan- 
perkataan diharapkan sampai kepada seseorang dengan cara halus, sehingga orang yang dimaksud atau yang dituju tidak merasa tersinggung atau merasa sakit hati.

Dalam kenyataan sehari-hari yang kita alami, kita mengetahui bahwa masyarakat itu terdiri atas kelompok-kelompok individu yang menjadi anggota masyarakat tersebut dan hidup dalam lingkungan tertentu, menunjukan kesatuan, memiliki kebiasaan-kebiasaan tertentu. Dengan demikian masyarakat merupakan bentuk pengelompokan individu manusia yang menunjukkan aktivitas bersama yang tampak dalam interaksi di antara anggota-anggota dimana kebutuhankebutuhan individu anggota masyarakat hanya dapat dipenuhi dengan jalan berinteraksi satu sama lain.

Sisindiran tumbuh dan berkembang di dalam masyarakat (Sunda), bahasanya mudah dipahami seperti bahasa sehari-hari. Dalam sastra Indonesia sisindiran disebut pantun merupakan puisi rakyat yang sangat digemari masyarakat di kalangan anak-anak, remaja maupun orang tua. Sisindiran dapat mengungkapkan atau mencerminkan perasaan, keadaan lingkungan, dan situasi masyarakat desa, petani, pendidik, dan lain sebagainya. Itulah yang menyebabkan gendre sisindiran ini sangat memasyarakat. Dalam masa sekarangpun dapat dikatakan bahwa sisindiran erat hubungannya dengan seni kawih, serta dapat dibawakan dalam bermacam-macam jenis kesenian misalnya wayang golek, calung, reog, upacara pernikahan, di samping itu sering digunakan untuk bergurau.

Dilihat dari fungsinya, maka sisindiran berfungsi sebagai pengendali tingkahlaku anggota-anggota masyarakat agar mereka patuh dan taat pada kaidah-kaidah, norma-norma, atau aturan-aturan yang telah ada dalam masyarakat. Atau dapat pula dikatakan sebagai fungsi untuk mengarahkan tingkah laku anggota-anggota masyarakat, agar tidak menyimpang dari ketentuanketentuan yang ada dalam kehidupan masyarakat.

Melalui puisi sisindiran, diharapkan akan mengetahui dan memahami antara yang salah dan yang benar, serta menguntungkan dan merugikan bagi dirinya. Ungkapan-ungkapan dalam sisindiran diharapkan menjadi bahan bacaan yang dapat menuntun generasi berikut ke jalan kebaikan melalui ungkapan yang disampaikan secara langsung atau tidak langsung (menyindir).

Norma dan nilai yang digali dari puisi sisindiran yang masih relevan dengan situasi dan kondisi masyarakat sekarang perlu disebarluaskan ke kalangan masyarakat luas, melalui penerbitan dan media komunikasi lainnya, agar mereka memilki acuan atau pedoman hidup yang berakar dari budaya sendiri yang pada gilirannya acuan tersebut akan berfungsi sebagai saringan (filter) dalam menerima pengaruh budaya asing. 


\section{DAFTAR SUMBER}

Atja dan Saleh Danasasmita. 1981.

Sanghiyang Siksa Kandang Karesian. Proyek Pengembangan Permuseuman, Bandung Jawa Barat.

Ekadjati, Edi S. Dkk. 1983.

Wawacan Carios Munada. Departemen Pendidikan dan Kebudayaan Direktorat Jenderal Kebudayaan Direktorat Sejarah dan Nilai Tradisional Bagian Proyek Penelitian dan Kebudayaan Nusantara, Jakarta.

RE Bratakusumah dan Mas Adinata. 1979.

Sisindiran. Jakarta: Proyek Penerbitan Buku Bacaan dan Sastra Indonesia dan Daerah. Departemen Pendidikan dan Kebudayaan.

Rosidi, Ajip. 1970.

Carita Mundinglaya Di Kusumah. Bandung: Proyek Penelitian Pantun.

Sutrisno, Sulastin. 1981.

Relevansi Filologi. Yogyakarta Universitas Gajah Mada.

Kamus Besar Bahasa Indonesia. 1990.

Jakarta : Balai Pustaka.

Lembaga Basa \& Sastra Sunda. 1975

Kamus Umum Basa Sunda. Bandung: Tarate. 